\title{
Characteristics of burns in children - results of a Polish multicentre study
}

\author{
Agata M. Kawalec \\ Department of Hygiene, Wroclaw Medical University, Wroclaw, Poland
}

\section{ABSTRACT}

\begin{abstract}
Aim of the study: To characterise burns in Polish children according to sex, age group, and depth of burn. Material and methods: The anonymous survey included 200 children under 18 years old hospitalised due to burns in five Polish hospitals. The location of burn was characterised in detail and also in agreement with ICD-10 classification. The surface of burned skin (\% TBSA) was counted with use of Lund-Bowder chart for children under 16 years old and with the rule of nines for children over 16 years old. Depth of burn was assessed clinically. The study was accepted by the Bioethical Committee of Wroclaw Medical University. Statistical analysis of the obtained data was performed using Excel and Statistica v. 12.

Results: $60 \%$ of the burned children were boys (120) and in $40 \%$ were girls (80). Children under one year old comprised $50.5 \%$ of all participants of the study. Among participants of the study thermal burns comprised $93.0 \%$, chemical burns $-4.5 \%$, and electrical burns $-2.5 \%$ of all cases. Boys underwent chemical (5.0\% vs. $3.8 \%$ ) and electrical (3.3\% vs. $1.3 \%$ ) burns more than girls ( $p>0.05)$. There were statistically significant differences in the type of burn in different age groups. In $84.5 \%$ the thermal burns were caused by hot liquid, in 3.7\% by a hot object, and in $4.3 \%$ by flame. Most commonly burns affected the trunk (57\%) and upper extremity (50\%). The average burn surface area was $8.26 \pm 7.87 \%$ TBSA. Most burns did not extend to the full depth of the skin (I degree - 3\%, II degree - 61.5\%).

Conclusions: Prevention programs should be aimed at minimising the risk of burns in the group at highest risk - children under one year old.
\end{abstract}

KEY WORDS:

children, Poland, burns.

\section{INTRODUCTION}

Burns are known to be one of the most devastating types of trauma that can occur in children. Decreasing trends in the number of burns are observed in many countries $[1,2]$. Furthermore, the problem of burns in children remains due to the complications and sequels of burn injury such as contractures, scars, and loss of function $[3,4]$.
Moreover, the assessment of child and adolescent injury prevention and safety promotion in Poland made by Malinowska-Cieślik et al. revealed that child home safety related to prevention of falls, burns and scalds, choking, and strangulation has not received adequate attention [5]. Information about the epidemiology of burns in children can provide a means for targeting efforts in burn prevention [6].

It is well known that children in low- to middle-income countries are at higher risk of sustaining severe

\section{ADDRESS FOR CORRESPONDENCE:}

Agata M. Kawalec, Department of Hygiene, Wroclaw Medical University, 7 Mikulicza-Radeckiego St.,

50-435 Wrocław, Poland, ORCID: 0000-0002-5030-9546, e-mail: agata_kawalec@wp.pl 
burns than those in high-income countries [3]. However, according to the analysis of medical rescue operations performed by medical rescue teams from all over Poland in patients with burn wounds, made by Nadolny et al., the problem of burns remains significant in Polish emergency medicine [7]. Moreover, even in wealthy societies sequels of burn injury in childhood can significantly affect survivors' life quality.

The aim of this study was to characterise burns in children according to sex, age group, and depth of burn.

\section{MATERIAL AND METHODS}

An anonymous survey included 200 children under 18 years old hospitalised due to burns in give Polish hospitals: Department of Paediatric Surgery, Marciniak Hospital in Wrocław (146 patients); Department of Paediatric Surgery, Burns, and Paediatric Urology "Zdroje" in Szczecin (31 patients); Department of Paediatric Surgery, WCM in Opole (16 patients); Department of Plastic Surgery, SCM in Polanica-Zdrój (five patients); Clinic of Paediatric Surgery and Paediatric Urology in Wrocław (two patients).

The questionnaire had two parts. The first part was filled in by parents/caregivers and included questions about the circumstances of the injury, housing conditions, the economic situation of the family, and family structure. The second part was filled in by the doctor and provided information about the location of the burn, the area of burned skin (\% TBSA), the depth of the injury, the type of treatment (surgical or preservative), and the length of the hospitalisation. The location of burn was charactersed in detail and also in agreement with ICD-10 classification. The area of burned skin (\% TBSA) was measured with use of Lund-Bowder chart for children under 16 years old and with rule of nines for children over 16 years old. The depth of burn was assessed clinically. The severity of burns was assessed with use of the American Burn Association (ABA) scale.

Inclusion criteria were:

1) hospitalisation due to burn,

2) agreement of caregivers and patient over 16 years old to participate in the study,

3) patient age under 18 years.

The exclusion criterion was disagreement of the caregiver/patient to participate in the study.

The study was accepted by the Bioethical Committee of Wroclaw Medical University (decision no. KB -
109/2014, no. KB - 305/2015, no. KB - 493/2015, no. $\mathrm{KB}-518 / 2015$, and no. KB - 141/2016). The study was performed from 5.03.2014 to 5.03.2016.

Statistical analysis of the obtained data was performed using Excel and Statistica v. 12.

\section{RESULTS}

\section{AGE AND SEX}

$60 \%$ of the burned children were boys (120) and in $40 \%$ were girls (80). Children under one year old comprised $50.5 \%$ of all participants of the study. $88.5 \%$ of the participants were children under five years old. The average age of the burned children in the study group was $\mathrm{M} \pm \mathrm{SD}=3.85 \pm 2.71$. Children were divided into four age groups (Table 1). There were no statistically significant differences between girls and boys in the different age groups $(p>0.05)$.

\section{TYPE OF INJURY}

Burns can be classified as thermal, chemical, electrical, or radiation burns. Among participants of the study, thermal burns comprised $93.0 \%$, chemical burns $-4.5 \%$, and electrical burns $-2.5 \%$ of all cases. The type of burn injury was similar in both sexes. Boys underwent chemical $(5.0 \%$ vs. $3.8 \%$ ) and electrical (3.3\% vs. $1.3 \%$ ) burns more than girls, but the differences were not statistically significant $(p>0.05)$. There were statistically significant differences in the type if burn in different age groups (Table 2). In $84.5 \%$ the thermal burns were caused by hot liquid (158 cases), in $3.7 \%$ (7 cases) by hot objects, and in $4.3 \%$ (8) by flame. Teenagers (age range: $12-17$ years) more often than younger children $(<5$ years old) were hospitalised due to burns caused by flames $(p<0.001)$. Scalds occurred more often in children under two years old than in children between 12 and 17 years old $(p<0.001)$. The aetiologic factors of scalds were tea $(28.7 \%)$, water $(28.7 \%)$, coffee (21\%), milk (5.1\%), soup (5.7\%), and oil (4.5\%).

\section{CHARACTERISTICS OF BURN INJURY}

Burn injury can be classified according to the anatomic location, extension, and depth.

Anatomic location of burns assessed according to the classification ICD-10 was similar in both sexes $(p>0.05)$

TABLE 1. Number of burned children in different age groups

\begin{tabular}{|c|c|c|c|c|c|c|c|c|c|}
\hline \multirow[t]{3}{*}{ Sex } & \multicolumn{8}{|c|}{ Age group (years old) } & \multirow{3}{*}{$\begin{array}{c}\text { Test } \chi^{2} \\
p\end{array}$} \\
\hline & \multicolumn{2}{|c|}{$\begin{array}{l}\text { Under } 2 \\
(n=149)\end{array}$} & \multicolumn{2}{|c|}{$\begin{array}{c}3-5 \\
(n=29) \\
\end{array}$} & \multicolumn{2}{|c|}{$\begin{array}{c}6-11 \\
(n=7)\end{array}$} & \multicolumn{2}{|c|}{$\begin{array}{c}12-17 \\
(n=15)\end{array}$} & \\
\hline & $n$ & $\%$ & $n$ & $\%$ & $\bar{n}$ & $\%$ & $\bar{n}$ & $\%$ & \\
\hline Girls & 56 & 37.6 & 16 & 55.2 & 1 & 14.3 & 7 & 46.7 & 0.148 \\
\hline Boys & 93 & 62.4 & 13 & 44.8 & 6 & 85.7 & 8 & 53.3 & \\
\hline
\end{tabular}


TABLE 2. Type of burn and age of children

\begin{tabular}{|c|c|c|c|c|c|c|c|c|c|}
\hline \multirow[t]{3}{*}{ Type of burn } & \multicolumn{8}{|c|}{ Age group (years old) } & \multirow{3}{*}{$\begin{array}{c}\text { Test } \chi^{2} \\
p\end{array}$} \\
\hline & \multicolumn{2}{|c|}{$\begin{array}{c}\text { Under } 2 \\
(n=149)\end{array}$} & \multicolumn{2}{|c|}{$\begin{array}{c}3-5 \\
(n=29) \\
\end{array}$} & \multicolumn{2}{|c|}{$\begin{array}{c}6-11 \\
(n=7) \\
\end{array}$} & \multicolumn{2}{|c|}{$\begin{array}{c}12-17 \\
(n=15) \\
\end{array}$} & \\
\hline & $n$ & $\%$ & $n$ & $\%$ & $n$ & $\%$ & $n$ & $\%$ & \\
\hline Thermal & 142 & 95.3 & 26 & 89.7 & 7 & 100.0 & 11 & 73.3 & 0.011 \\
\hline Chemical & 7 & 4.7 & 1 & 3.4 & 0 & 0.0 & 1 & 6.7 & 0.901 \\
\hline Electric & 0 & 0.0 & 2 & 6.9 & 0 & 0.0 & 3 & 20.0 & $<0.001$ \\
\hline
\end{tabular}

TABLE 3. Anatomic site of burn (according to the classification ICD-10) and age of children

\begin{tabular}{|c|c|c|c|c|c|c|c|c|c|}
\hline \multirow[t]{3}{*}{ Anatomic site of burn } & \multicolumn{8}{|c|}{ Age group (years old) } & \multirow{3}{*}{$\begin{array}{c}\text { Test } \chi^{2} \\
p\end{array}$} \\
\hline & \multicolumn{2}{|c|}{$\begin{array}{l}\text { Under } 2 \\
(n=149)\end{array}$} & \multicolumn{2}{|c|}{$\begin{array}{c}3-5 \\
(n=29)\end{array}$} & \multicolumn{2}{|c|}{$\begin{array}{c}6-11 \\
(n=7) \\
\end{array}$} & \multicolumn{2}{|c|}{$\begin{array}{c}12-17 \\
(n=15)\end{array}$} & \\
\hline & $n$ & $\%$ & $n$ & $\%$ & $n$ & $\%$ & $n$ & $\%$ & \\
\hline Head and neck & 30 & 20.1 & 1 & 3.4 & 0 & 0.0 & 1 & 6.7 & 0.017 \\
\hline Trunk & 94 & 63.1 & 11 & 37.9 & 1 & 14.3 & 8 & 53.3 & 0.008 \\
\hline Shoulder and upper limb (except wrist and hand) & 62 & 41.6 & 8 & 27.6 & 1 & 14.3 & 8 & 53.3 & 0.167 \\
\hline Hand and wrist & 21 & 14.1 & 7 & 24.1 & 1 & 14.3 & 6 & 40.0 & 0.060 \\
\hline Hip and lower limb (except ankle and foot) & 32 & 21.5 & 12 & 41.4 & 5 & 71.4 & 5 & 33.3 & 0.005 \\
\hline Ankle and foot & 10 & 6.7 & 4 & 13.8 & 2 & 28.6 & 1 & 6.7 & 0.148 \\
\hline Internal organs & 6 & 4.0 & 1 & 3.4 & 0 & 0.0 & 1 & 6.7 & 0.898 \\
\hline
\end{tabular}

Proportions do not add up to 100 because more than one answer was marked in many cases

TABLE 4. The extent of burns in different age groups

\begin{tabular}{|l|c|c|c|c|c|}
\hline \multirow{2}{*}{$\begin{array}{l}\text { Surface of burn } \\
\text { (\% TBSA) }\end{array}$} & \multicolumn{4}{|c|}{ Age group (years old) } & Kruskal-Wallis \\
& $\begin{array}{c}\text { Under } 2 \\
(n=149)\end{array}$ & $\begin{array}{c}3-5 \\
(n=29)\end{array}$ & $\begin{array}{c}6-11 \\
(n=7)\end{array}$ & $\begin{array}{c}12-17 \\
(n=15)\end{array}$ & $\begin{array}{c}\text { test } \\
\text { yyyyn}\end{array}$ \\
\hline M \pm SD & $8.8 \pm 7.8$ & $6.2 \pm 5.0$ & $12.3 \pm 17.6$ & $5.3 \pm 3.3$ & $5(2 ; 8)$ \\
\hline Me (Q1; Q3) & $6(4 ; 12)$ & $4(2 ; 8)$ & $4(3 ; 14)$ & $1-10$ & \\
\hline Min-max & $1-70$ & $1-18$ & $1-51$ & \\
\hline
\end{tabular}

TABLE 5. Treatment of burns in different age groups

\begin{tabular}{|c|c|c|c|c|c|c|c|c|c|}
\hline \multirow[t]{3}{*}{ Treatment } & \multicolumn{8}{|c|}{ Age group (years old) } & \multirow{3}{*}{$\begin{array}{c}\text { Test } \chi^{2} \\
p\end{array}$} \\
\hline & \multicolumn{2}{|c|}{$\begin{array}{c}\text { Under } 2 \\
(n=149)\end{array}$} & \multicolumn{2}{|c|}{$\begin{array}{c}3-5 \\
(n=29)\end{array}$} & \multicolumn{2}{|c|}{$\begin{array}{c}6-11 \\
(n=7)\end{array}$} & \multicolumn{2}{|c|}{$\begin{array}{c}12-17 \\
(n=15)\end{array}$} & \\
\hline & $n$ & $\%$ & $n$ & $\%$ & $n$ & $\%$ & $n$ & $\%$ & \\
\hline Conservative & 107 & 71.8 & 20 & 69.0 & 3 & 42.9 & 7 & 46.7 & \multirow[t]{2}{*}{0.205} \\
\hline Surgical & 33 & 22.1 & 7 & 24.1 & 4 & 57.1 & 7 & 46.7 & \\
\hline
\end{tabular}

TABLE 6. Duration of hospital stay in different age groups

\begin{tabular}{|l|c|c|c|c|c|}
\hline \multirow{2}{*}{$\begin{array}{l}\text { Duration of hospital } \\
\text { stay (days) }\end{array}$} & \multicolumn{4}{|c|}{ Age group (years old) } & Test $\chi^{2}$ \\
\cline { 2 - 5 } & $\begin{array}{c}\text { Under 2 } \\
(n=149)\end{array}$ & $\begin{array}{c}3-5 \\
(n=29)\end{array}$ & $\begin{array}{c}6-11 \\
(n=7)\end{array}$ & $\begin{array}{c}12-17 \\
(n=15)\end{array}$ & \multirow{2}{*}{0.046} \\
\hline M SD & $6.9 \pm 4.2$ & $8.6 \pm 5.5$ & $14.3 \pm 13.6$ & $15.3 \pm 13.5$ & \\
\hline Me (Q1; Q3) & $6(4 ; 9)$ & $7.5(4 ; 13)$ & $11(4 ; 21)$ & $11(6 ; 20)$ & \\
\hline Min-max & $1-17$ & $1-20$ & $1-38$ & $3-48$ & \\
\hline
\end{tabular}


but differed significantly in the age groups (Table 3). Most commonly burns affected the trunk (57\%) and upper extremity (50\%).

In the cases, in whom the circumstances of the injury were known, they were: spilling hot liquid (163), drinking liquid (7), touching a hot surface/object (8), burning with a flame (6), putting fingers in electrical outlet (2), contact with high-voltage lines (2), and gas explosion (1).

\section{THE EXTENT AND DEPTH OF BURNS}

The extent of the burn, defined as the percentage of total body surface area (\% TBSA), is one of the most important parameters characterising this injury (Table 4). The average burn surface area was $8.26 \pm 7.87 \%$ TBSA. The average burn surface in boys was $0.44 \%$ higher than in girls $(8.00 \%$ vs. $8.44 \%)$, but the difference was not statistically significant $(p=0.076)$.

According to the depth of burns, they can be classified into first degree (superficial), second degree (partial thickness), third degree (full thickness), or fourth degree (affects the entire depth of the skin, underlying fat, muscles, bones). Most of the burns did not extend to the full depth of the skin (I degree - 3\%, II degree - 61.5\%). 30\% of children had burns assessed as III degree and $1.5 \%$ as IV degree. No significant differences were found between burn depth in girls and boys $(p=0.397)$ or in different age groups $(p=0.083)$.

Most cases (68.5\%) did not require surgical treatment. The differences in the type of treatment in different age groups are presented in Table 5. Children under two years old were treated conservatively significantly more often than those aged $12-17$ years $(76.4 \%$ vs. $50.0 \% ; p=0.039)$.

The average length of hospital stay was $8.07 \pm 6.48$ days. Boys were hospitalised longer $(8.63 \pm 7.32)$ than girls (7.26 \pm 4.98$)$, but the differences were not statistically significant $(p>0.05)$. Patients aged $12-17$ years were hospitalised longer than those under two years old (Table 6). The difference between length of hospital stay in these two age groups was statistically significant.

The average hospital stay of children ages 12-17 years was longer than those under two years old (11 days vs. 6 days; $p<0.05$ ) (Table 6). The difference between length of hospital stay in these two age groups was statistically significant $(p=0.014)$. Children under two years old were treated conservatively more often than those aged 12-17 years $(76.4 \%$ vs. $50.0 \%$; $p=0.039)$.

\section{BURNS IN THE PAST AND FAMILY HISTORY}

The answers to the question about burns in past events revealed that a total of 12 children were burnt in the past (seven of them were under two years old), and one patient required hospitalisation due to burn injury in the past. In 37 cases children required hospitalisation due to reasons other than burns in the past. In 40 cases other family members suffered from burns in the past.

\section{FAMILY, HOUSING CONDITIONS, ECONOMIC SITUATION}

The analysis of cases in whom the family structure was known revealed that children were in two-parent families (150; 82.3\%), single-parent families (15; 8.3\%), and multigenerational families (13; 7.2\%). The burnt child was the only child in the family in $44.8 \%$. In $37.7 \%$ there were two children in the family. In $17.5 \%$ of families there were three or more children.

In $89 \%$ the parents assessed the housing conditions as very good or good; in $11 \%$ they assessed them as average or poor. In $75 \%$ the caregivers assessed the economic situation as very good or good; in $25 \%$ they assessed it as average or poor.

\section{DISCUSSION}

In the study $60 \%$ of victims were boys. Similar results were obtained by Nadolny, who analysed the trips of emergency medical teams to patients diagnosed with burns throughout Poland [7]. Similarly, Noskiewicz et al. in a retrospective analysis performed on 310 paediatric patients hospitalised for burns in the years 2010-2017 noticed that the majority of them $(66.8 \%, 207$ patients) were boys [8]. The same trends were noticed by Matuszczak et al., Brodzińska et al., Topczewska-Cabanek et al., and Gontko et al. [9-13]. Also, Mitchell et al. in a study that investigated children $<18$ years old treated for burns in United States (US) emergency departments from 1990 to 2014 using data from the National Electronic Injury Surveillance System, in which most patients (58.4\%) were boys [1]. Similar observations were noticed in the other countries - most burned patients were male [2].

In the study $88.5 \%$ participants were children less than five years old. In the study of Noskiewicz at al. burns occurred most frequently in children between the first and third year of life [8]. Brodzińska et al. also indicated that children who undergo hospital treatment are mostly aged 1-2 years old $[10,11]$. Also, Gontko et al. revealed that most often this type of injury was observed in children between one and two years [13].

Also, other Polish studies on burns in children revealed that the most common cause of burns were hot liquids [8-11, 13]. Similar observations were made in different countries. The analysis of the epidemiology and outcomes of paediatric burns over 35 years at Parkland Hospital revealed that the most common causes of admission were scald (42\%), flame (29\%), and contact burns (10\%) [14]. In the study of den Hollander et al. common causes for the burns in children were: hot liquids (71\%) and open flame (24\%) [15]. 
The results of other studies performed in the Polish population indicate that in most cases burnt children were treated conservatively $[8,9]$. In the study most cases $(68.5 \%)$ did not require surgical treatment. Children under two years old were treated conservatively significantly more often than those aged $12-17$ years $(76.4 \%$ vs. $50.0 \% ; p=0.039$ ). The differences in the type of treatment in different age groups may be associated with the fact that, according to the indications, every burned infant (regardless of the degree and area of the burn) requires hospital observation, which increases the number of conservatively treated patients in this age group, while not all burned teenagers require hospitalisation. Kurnatowski pays attention on the fact that age under two years puts a child at risk and is an indication to hospitalisation [16]. Also, in the study of Matuszczak et al. about hand burns in children, most patients with hand burns (88\%) were treated conservatively [17].

In the study most burns affected the trunk and upper extremity. A similar observation was made by Gontko et al. in their study that involved 190 children treated in the Paediatric Surgery Department of SZOZ nad Matką i Dzieckiem in Poznań from 1 January to 31 December of 2010 [13]. The analysis of the structure of burns in children in Lower Silesia also revealed that upper the extremity was often affected [18]. In the study of TopczewskaCabanek et al. most of burns affected the thorax [11].

The average burn surface area in participants of the study was $8.26 \pm 7.87 \%$ TBSA, which was smaller than in the study of Gontko et al., in which the average TBSA was $12.13 \%$ TBSA \pm SD $8.64 \%$ [13]. In the study of den Hollander et al. the mean total body surface area (TBSA) burned for children was $12 \%$ (interquartile range 8-25\%) [15].

Delgado et al. revealed that lack of water supply, low income, and crowding were associated with an increased risk of burn injury in children, while the presence of a living room and better maternal education were protective factors [19]. Vendrusculo et al. noticed that the majority of victims of burn accidents in the domestic environment had family income lower than two times the minimum wage [20]. Also, in the study of epidemiologic characteristics, knowledge, and risk factors of unintentional burns in rural children in Zunyi (Southwest China), children living in high-income families were less likely to sustain burns when compared with middle-class families [21]. In contrast to that, in our study $75 \%$ of the caregivers assessed the economic situation as very good or good. However, the results are limited because the question was about subjective assessment of the economic situation. Natterer et al. also concluded in the results of their study that there does not seem to be an increased risk in the immigrant population or in low-economic-status families [22].

In the study of Palmieri et al. about paediatric soup scald burn injuries, households had a mean of $3.0 \pm 0.3$ children in residence [23]. In our study, only in $17.5 \%$ of families were there three or more children.

In our study, most of the children lived in two-parent families. Adronicus et al. suggest that children with non-accidental burns were more likely to come from single-parent families [24]. Among the potential factors that can lead to increased risk of injury in single-parent families are lower socioeconomic status of the family and lack of adult caregiver supervision.

\section{CONCLUSIONS}

Most paediatric patients hospitalised due to burns were under five years old and were more frequently boys. The most common type of injury was thermal burn, usually caused by a hot liquid. The injury usually affected the trunk and upper extremity, did not extend to the full depth of the skin, and was treated conservatively.

That means that the prevention programs should be aimed at minimising the risk of burns in the group at highest risk: children under one year old, and should concentrate on education of caregivers about situations that put their children at risk of burn injury and on limiting the possibilities of injury.

\section{DISCLOSURE}

The author declares no conflict of interest.

\section{REFERENCES}

1. Mitchell M, Kistamgari S, Chounthirath T, et al. Children Younger Than 18 Years Treated for Nonfatal Burns in US Emergency Departments. Clin Pediatr (Phila) 2020; 59: 34-44.

2. Saavedra PA, deBrito ES, Areda CA, et al. Burns in the Brazilian Unified Health System: a review of hospitalization from 2008 to 2017. Int J Burns Trauma 2019; 15; 9: 88-98.

3. Meng F, Zuo KJ, Amar-Zifkin A, et al. Pediatric burn contractures in low- and lower middle-income countries: A systematic review of causes and factors affecting outcome. Burns 2019; 5. pii: S03054179(18)31114-8

4. Oosterwijk AM, Mouton LJ, Akkerman M, et al. Course of prevalence of scar contractures limiting function: A preliminary study in children and adolescents after burns. Burns 2019; 45: 1810-1818.

5. Malinowska-Cieślik M, Balcerzak B, Mokrzycka A, et al. Assessment of child and adolescent injury prevention and safety promotion in Poland. Zdrowie Publiczne i Zarządzanie 2012; 10: 80-94.

6. Johnson DM, Gilstrap J, White LJ, et al. Fireworks and Seafood Boils: The Epidemiology of Burns in Louisiana. J Burn Care Res 2019; 26: 159 .

7. Nadolny K, Ładny JR, Ślęzak D, et al. Analysis of medical rescue operations performed by medical rescue teams from all over poland in patients with burn wounds. Wiad Lek 2019; 72: 26-30.

8. Noskiewicz J, Rzanny-Owczarzak M, Mańkowski P. Paediatric burn injuries - retrospective evaluation of applied therapeutic management. Pediatr Pol 2018; 93: 433-437.

9. Matuszczak E, Dębek W, Chomicz A, et al. Etiology and epidemiology and results of treatment children with burns. Pediatr Pol 2011; 86: 254-259. 
10. Brodzińska B, Czaja-Bulsa G, Marasz A, et al. Epidemiology of burns in hospitalized children from the Western Pomerania region in Poland in 1985-2010. Prog Health Sci 2017; 7: 99-106.

11. Brodzińska B. [Burns and scalds in children of the Western Pomerania region in the 1980s and today]. Pom J Life Sci 2017; 63: 82-88.

12. Topczewska-Cabanek A, Pernach A, Nitsch-Osuch A, et al. [Burns as a cause of hospitalising children in one of Warsaw's hospitals in 2008-2012]. Fam Med Prim Care Rev 2014; 16: 297-299.

13. Gontko K, Ratajczak K, Naskręt M. [Burns in children in the Wielkopolska Region in 2010]. Anestezjol Rat 2012; 6: 402-408.

14. Saeman MR, Hodgman EI, Burris A, et al. Epidemiology and outcomes of pediatric burns over 35 years at Parkland Hospital. Burns 2016; 42: 202-208.

15. den Hollander D, Albert M, Strand A, et al. Epidemiology and referral patterns of burns admitted to the Burns Centre at Inkosi Albert Luthuli Central Hospital, Durban. Burns 2014; 40: 1201-1208.

16. Kurnatowski W. Ciężkie oparzenia - charakterystyka i wskazania terpeutyczne. Zakażenia 2003; 2: 83-88.

17. Matuszczak E, Dębek W, Ciszyńska M, Chomicz A. Oparzenia rąk - postępowanie i wyniki leczenia. Pediatr Pol 2011; 86: 260-262.

18. Kawalec A, Pawlas K. [Structure of burns in children in Lower Silesia (Poland) in 2010-2012]. Probl Hig Epidemiol 2014; 95: 394-399.

19. Delgado J, Ramírez-Cardich ME, Gilman RH, et al. Risk factors for burns in children: crowding, poverty, and poor maternal education. Inj Prev 2002; 8: 38-41.

20. Vendrusculo TM, Balieiro CR, Echevarría-Guanilo ME, et al. Burns in the domestic environment: characteristics and circumstances of accidents. Rev Lat Am Enfermagem 2010; 18: 444-451.

21. Shi S, Yang H, Hui Y, et al. Epidemiologic characteristics, knowledge and risk factors of unintentional burns in rural children in Zunyi, Southwest China. Sci Rep 2016; 6: 35445.

22. Natterer J, de Buys Roessingh A, Reinberg O, Hohlfeld J. Targeting burn prevention in the paediatric population: a prospective study of children's burns in the Lausanne area. Swiss Med Wkly 2009; 139: 535-539.

23. Palmieri TL, Alderson TS, Ison D, et al. Pediatric soup scald burn injury: etiology and prevention. J Burn Care Res 2008; 29: 114-118.

24. Andronicus M, Oates RK, Peat J, et al. Non-accidental burns in children. Burns 1998; 24: 552-558. 